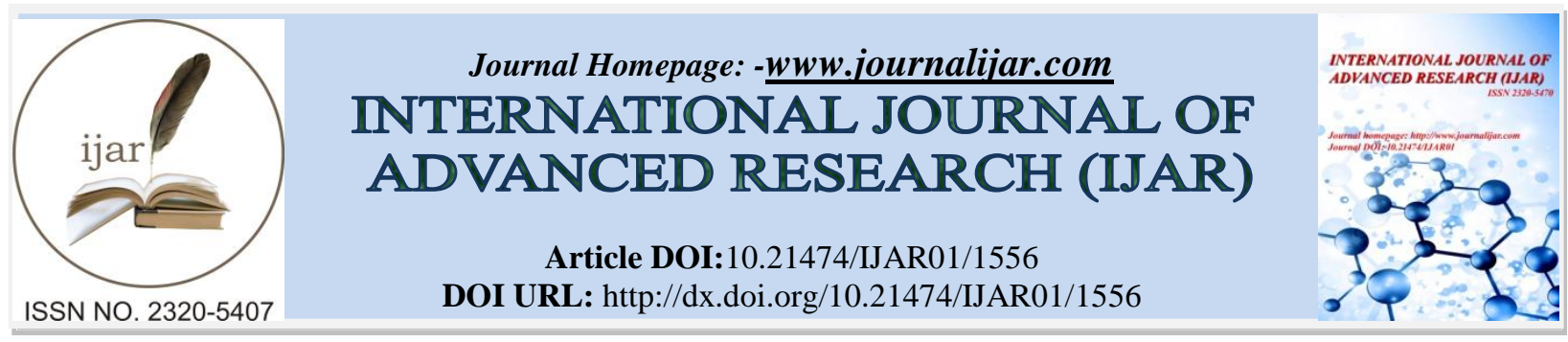

RESEARCH ARTICLE

\title{
THE EVALUATION OF HYOID BONE IN DIFFERENT SKELETAL MALOCCLUSIONS AND GROWTH PATTERNS IN INDIAN POPULATION.
}

\section{Jee Hun Kim ${ }^{1}$, Nakul R Raval ${ }^{1}$ and Amol S Patil ${ }^{2}$}

1. Intern, BharatiVidyapeeth Deemed University Dental College \& Hospital, Pune, India.

2. Professor, Department of Orthodontics, BharatiVidyapeeth Deemed University Dental College \& Hospital, Pune, India.

\section{Manuscript Info}

\section{…........}

Manuscript History

Received: 15 July 2016

Final Accepted: 10 August 2016

Published: September 2016

Keywords:-

Hyoid position, Orthodontics, Jarabak Ratio, Skeletal, Malocclusion, Growth

Patterns, Indianpopulation

\section{Abstract}

Objective: The aim of the study was to investigate the relationship of the different skeletal malocclusions as well as various growth patterns to the position and orientation of the hyoid bone.

Materials and methods: A total of 60 pretreatment digital lateral cephalograms were selected according to the criteria and grouped into 3 groups, group 1: Class I $(n=20)$, group 2: Class II $(n=20)$ and group 3: Class III $(n=20)$. The original 60 lateral cephalograms were also grouped under three different growth patterns into hyperdivergent $(n=17)$, hypodivergent $(n=24)$ and neutral $(n=19)$ which were given according to Jarabak. Lateral cephalograms were traced and analysed on different linear and angular parameters such as H-NSL, H-FH, HNL, H-Pog, H-Me, H-C3, NSH and MPH. The arithmetic mean and standard deviation values were calculated for each measurement. Independent sample $t$ - test was performed to compare the difference between the skeletal classes as well as with the growth patterns.

Result: The linear measurements of H-FH, H-NL, H-Pog, H-Me, HC3 showed statistically significant differences in Class I, Class II, and Class III (p-vaule $=0.03,0.01,0.0,0.0$ and 0.009 respectively). The angular measurements of SNA, SNB, ANB, SNH were also statistically significant (p-value $=0.006, \quad 0.0, \quad 0.0$ and 0.030 respectively) indicating the differences in respective class malocclusions. However, in the study that was grouped according to different growth patterns, viz. hyperdivergent(Hp), hypodivergent(Ho), and neutral $(\mathrm{Nt})$ did show statically significant differences. ( $p$-value $<0.05$ ).

Conclusion: The hyoid bone position and orientation is different in different skeletal malocclusions. In class III malocclusion, the hyoid bone is more anteriorly and inferiorly placed. In class II malocclusion, the hyoid bone position is more posterior and more superior. The anteroposterior dimensions in different class malocclusions remained constant. No relationship could be found between different facial morphologies (growth patterns) and hyoid bone position as well as orientation.

CopyRight, IJAR, 2016,. All rights reserved.

Corresponding Author:-Amol S Patil MDS, PhD

Address:- Professor, Department of Orthodontics, Bharati Vidyapeeth Deemed University Dental College \& Hospital, Pune, India. 


\section{Introduction:-}

Modern orthodontics takes into account of balance between dentofacial complex as a whole and the position of hyoid bone in relation to different malocclusion has intrigued and attracted many researchers. The attachment of muscles of tongues such as genioglossus and hyoglossus can be found on the hyoid bone and the position of the tongue apparently changes with the bone of its attachment. Such changes in position of tongue can affect the pharyngeal airway space and this is evident in orthognathic surgeries. Various authors ${ }^{[1,2]}$ have proved that the mandibular changes influence hyoid bone position during the entire postsurgical period, whereas stretching of suprahyoidal musculature seems to contribute to skeletal relapse.

The hyoid bone is unique in that it has no bony articulation with any other bone but is instead suspended in the soft tissue via ligaments and muscles ${ }^{[3]}$. Different muscles such as infra and suprahyoid muscles and genioglossus muscle influence the position of the hyoid bone ${ }^{[4,5]}$. According to Brodie ${ }^{[6]}$ the upright posture of the head involves the balance between the tensions of posterior neck muscles and anterior muscles such as masticatory, suprahyoid and infrahyoid groups in relative to occipital condyles. Hyoid bone position is, thus, a reflection of the relative tensions of the muscles, ligaments, and fascia attached to it. ${ }^{[7]}$

Being aware of the position of hyoid in different malocclusion and factors affecting its position can result in better orthodontic treatment without relapse and possible deficient pharyngeal airway space after orthodontic treatment as well as orthognathic surgery.

Various authors ${ }^{[8,9,10]}$ have attempted to study the hyoid bone in different malocclusions in different population. Nevertheless, the correlation between hypodivergent, hyperdivergent and neutral groups and the hyoid bone orientation as well as position as a separate entity has never studied before.

Despite of the previous study conducted there are controversies on position and orientation of hyoid bone in relation to anatomical landmarks. The purpose of the present study is to evaluate the position and orientation of the hyoid bone in skeletal Class I, Class II and Class III malocclusion. This study also aims to examine the correlation of Jarabak ratio and the different growth patterns namely Hypodivergent, Hyperdivergent and Neutral growth patterns with the orientation and position of the hyoid bone.

\section{Materials and methods:-}

60 Pretreatment digital lateral cephalograms were selected on the criteria as mentioned below. All cephalograms were of the same dimension, magnification and printed from the same machine.

Criteria for selection of the Cephalograms are as follows:

1) Subject should be of Indian Origin.

2) Subject should be healthy with no systemic diseases, signs of trauma or a congenital disease.

3) Subject should show no sign of previous orthodontic treatment.

4) Subject should be between the age group of 16years to 30years.

5) All Class I malocclusion patients had an ANB value between $1^{\circ}$ to $4^{\circ}$.

6) All Class II malocclusion patients had an amplitude of ANB value more $4^{\circ}$.

7) All Class III malocclusion patients had an amplitude of ANB value less than $1^{\circ}$.

Cephalograms were categorised into 3 major groups Group 1: Class I malocclusion, Group 2: Class II malocclusion, Group 3: Class III malocclusion. The original 60 cephalograms were also divided into 3 other groups namely Hyperdivergent (Hp), Neutral (Nt) and Hypodivergent (Ho). The criteria for the Jarabak's ratio was Hyperdivergent: 54-58\%, Neutral: 59-63\% and Hyperdivergent $64-80 \%{ }^{[8]}$ The number of Neutral growth patterns was 19, the number of Hyperdivergent growth patterns was 17 and the number of Hypodivergent growth patterns was 24. All Lateral cephalograms were taken by skilled and experienced technicians in a standard natural head position as recommended by Broadbent ${ }^{[11]}$. The cephalograms were manually traced by a single researcher with the help of a $0.5 \mathrm{~mm}$ thick lead pencil and a millimetre scale for the planes on Orthodontic tracing paper. For the linear measurements a millimetre precision digital vernier calliper was used for the registration of the reading, for the angular measurements a geometric protractor was used with a half degree approximation. They were again evaluated by a second researcher and the arithmetical mean of these readings were taken as the standard value for statistical evaluation and assessment. Beside routine anatomical designs the Cephalometric points and planes traced are given 
in table 1 and diagrammatically shown in figure 1 . The Cephalometric linear and angular measurements required are given in table 2.

Table 1:- Cephalometric landmarks and planes.

\begin{tabular}{|c|c|}
\hline S (sella turcica) & $\begin{array}{l}\text { the centre of the bony crypt occupied by the hypophysis } \\
\text { cerebri. }\end{array}$ \\
\hline $\mathrm{N}$ (nasion) & the anterior limit of the frontonasal suture. \\
\hline $\mathrm{P}$ (porion) & $\begin{array}{l}\text { the midpoint on the upper edge of the ear rod in the } \\
\text { external meatus. }\end{array}$ \\
\hline Or (orbitale) & the lower most point on the inferior rim of the orbit. \\
\hline A (subspinale) & $\begin{array}{l}\text { the deepest midline point on the premaxilla between the } \\
\text { anterior nasal spine and prosthion. }\end{array}$ \\
\hline B (supramentale) & $\begin{array}{l}\text { the most posterior point in the concavity between the } \\
\text { infradentale and pogonion. }\end{array}$ \\
\hline Go (gonion & $\begin{array}{l}\text { the midpoint of the contour connecting the ramus and } \\
\text { body of the mandible. }\end{array}$ \\
\hline Gn (gnathion) & $\begin{array}{l}\text { the most anterior and inferior point on the symphysis of } \\
\text { mandible. }\end{array}$ \\
\hline Me (menton) & the most inferior point on the symphysis of mandible. \\
\hline $\mathrm{H}$ (hyoidale) & $\begin{array}{l}\text { the most superior, anterior point on the body of the } \\
\text { hyoid bone. }\end{array}$ \\
\hline $\mathrm{C} 3$ & $\begin{array}{l}\text { the point at the most inferior and anterior position on the } \\
\text { third cervical vertebrae. }\end{array}$ \\
\hline Hy’ (Hy’point) & $\begin{array}{l}\text { The most posterior point of the greater horn of the hyoid } \\
\text { bone. }\end{array}$ \\
\hline ANS (anterior nasal spine) & Spina nasalis anterior \\
\hline PNS (posterior nasal spine) & Spina nasalis posterior \\
\hline SN (Sella-Nasion plane) & the line connecting points $\mathrm{S}$ and $\mathrm{N}$. \\
\hline FH (Frankfort horizontal plane) & the line connecting points $\mathrm{P}$ and Or. \\
\hline MP (Mandibular plane) & the line connecting points Go and $\mathrm{Gn}$ \\
\hline NL (Nasal line) & the line connecting through the points PNS and ANS. ${ }^{[7]}$ \\
\hline Hyoid axis (H axis) & The line that connects points $\mathrm{H}$ and $\mathrm{Hy}$ \\
\hline
\end{tabular}

Table 2:- cephalometric angular and linear measurements.

\begin{tabular}{|c|c|}
\hline ANB & $\begin{array}{l}\text { the angle joining point A to nasion (N) to point B (SNA- } \\
\text { SNB difference). }\end{array}$ \\
\hline $\mathrm{NSH}$ & the angle from nasion to sella to hyoidale. \\
\hline MPH & the angle from gonion to gnathion to hyoidale. \\
\hline SNA: & the angle from sella to nasion to point $\mathrm{A}$. \\
\hline SNB & the angle from sella to nasion to point $B$. \\
\hline H-SN perpendicular & $\begin{array}{l}\text { linear distance along a perpendicular from } \mathrm{H} \text { to the } \mathrm{S}-\mathrm{N} \\
\text { plane. }\end{array}$ \\
\hline H-FH perpendicular & $\begin{array}{l}\text { linear distance along a perpendicular from } \mathrm{H} \text { to the } \\
\text { Frankfort plane. }\end{array}$ \\
\hline H-NL perpendicular & $\begin{array}{l}\text { linear distance along a perpendicular from } \mathrm{H} \text { to the } \\
\text { palatal plane/nasal line. }\end{array}$ \\
\hline H-MP perpendicular & $\begin{array}{l}\text { linear distance along a perpendicular from } \mathrm{H} \text { to the } \\
\text { mandibular plane (Go-Gn). }\end{array}$ \\
\hline $\mathrm{H}-\mathrm{C} 3$ & linear distance between $\mathrm{H}$ and $\mathrm{C} 3$. \\
\hline $\mathrm{H}-\mathrm{Me}$ & linear distance between the hyoidale and mention. \\
\hline H-Go & linear distance between the hyoidale and the gonion. \\
\hline Jarabak ratio & $\begin{array}{l}\text { the ratio between the posterior facial height (S- Go) to } \\
\text { the anterior facial height }(\mathrm{N}-\mathrm{Me}) \text {. (Given in percentage) }\end{array}$ \\
\hline
\end{tabular}




\section{Statistical methods:-}

The data was statistically analysed with NCSS 11 Software (NCSSST, Kaysville, Utah, USA). Data was subjected to descriptive analysis for mean and standard deviation of all variables and ranges. Multiple $t$-test (independent sample $t$-test) was used for analysis of variance and a post hoc test (Bonferroni) was used for multiple comparisons. $\mathrm{P}<0.05$ was considered as the level for statistically significant data.

\section{Results:-}

The linear and angular measurements of the study have been tabulated in Table 3 . The linear measurements of $\mathrm{H}$ FH, H-NL, H-Pog, H-Me, H-C3 showed statistically significant differences in Class I, Class II and Class III (p-vaule $=0.03,0.01,0.0,0.0$ and 0.009 respectively). The angular measurements of SNA, SNB, ANB, SNH were statistically significant with p-value $0.006,0.0,0.0$ and 0.030 respectively indicating the differences in respective skeletal malocclusions. P-values have been paired for comparing the measurements in different classes and have been shown in Table 3(i). These findings show that hyoid bone is more inferiorly placed in Class III malocclusion compared to Class II which is more superiorly placed. The position of hyoid in relation to mandible using $\mathrm{H}-\mathrm{Pog}$, $\mathrm{H}-$ $\mathrm{Me}, \mathrm{H}-\mathrm{C} 3$ as the parameters has shown that mandible is more anteriorly placed in Class III malocclusion; and it is more posteriorly placed in Class II.The angular measurements of SNH, MPH shows that hyoid bone is anteriorly and inferiorly placed in Class III malocclusion and is more posteriorly and superiorly placed in Class II malocclusions. Linear measurement from cervical vertebra to the symphysis was least in Class III and the most in Class I, indicating vertical growth of mandible in class III which approximate the level of the cervical vertebra. The anterior-posterior position of the hyoid bone in relation to the cervical vertebra $(\mathrm{C} 3-\mathrm{H})$ again confirmed the previous reading that the patient with the class III malocclusion has more anteriorly placed hyoid bone. Class II, however, showed most close position with the cervical vertebra indicating its most posterior position among the classes.

However, in the study that was grouped according to different growth patterns or facial morphologies, viz. hyperdivergent $(\mathrm{Hp})$, hypodivergent $(\mathrm{Ho})$, and neutral $(\mathrm{Nt})$, p-values were more than $0.05(\mathrm{p}$-value $<0.05)$ as given in Table 4 and 4(i). Hence showing no statistically significant difference in any of the different growth patterns.

\section{Discussion:}

The statistically different values of the linear and angular measurements (eg. H-FH, H-NL, H-Pog, SNH, MPH) findings show that hyoid bone is more inferiorly placed in Class III malocclusion compared to Class II which is more superiorly placed. Similar observations were given by Mohammed Amayeri et al ${ }^{[13]}$, also by Carlos Aranha et al ${ }^{[14]}$. Some authors ${ }^{[15-20]}$ just used linear measurements and did not use angular integrations and hence the orientation of the hyoid couldn't be visualised in the $3 \mathrm{rd}$ dimension. While Ingervall ${ }^{[21]}$ only used the mandible as a reference for the comparison which is not a stable landmark which was further changed by Bibby in in the introduction of the hyoid triangle. However previous studies have shown the controversies about different position of hyoid bone in skeletal's class malocclusions.

Some authors $[22,23,24]$ reported the significant difference in position of hyoid bone depending upon the malocclusions. Adamidis et $\mathrm{al}^{[22]}$,studied the cephalometric radiographs of two groups of exhibiting Class I and Class III malocclusions. He found that hyoid bone tends to be more anteriorly placed in the group exhibiting Class III malocclusions. Opdebeeck et $\mathrm{al}^{[23]}$ analysed and compared linear and angular measurements for short face and long face syndrome and concluded that the characteristics of the long face and short face syndrome group can be explained by movement of hyoid bone in concert with the movement of mandible, tongue, cervical spine in both groups. According to them, the changes in mandibular position are related to hyoid bone changes and the hyoid position adapts to anterior-posterior changes in head posture ${ }^{[25,22,23]}$. On the other hands, some authors ${ }^{[18,26,27]}$ had advocated there are no significant differences among different class malocclusions.

Galvao $^{[14]}$ was the first one to use the SN line which represented the anterior base of the skull because of its routinary use in the cephalometric tracing and effortless localization and stability of the involved structures. In previous discussion, the hyoid bone was said to play an important role in the physiology of the swallowing. The swallowing reflex repeats interleaf approximately twice a minute while one is asleep hence the role of the the hyoid bone is an important one. ${ }^{[28]}$

Graber $^{[29]}$ on the other hand found the correlation between the position of the hyoid bone and and the mandibular morphology and hence found an affirmative explanation between the positive correlation. Stepovich ${ }^{[20]}$ also said that the hyoid bone assumes variable position from a person to another and the difference in it may also occur in a same 
sample of the patients after a short space of time. The measurement between the hyoid bone and some cranial points relatively distant from the hyoid or the plane may cause a large variation even with slightest of the variation even thou the difference are just apparent ones. That is why the relation between the mandibular symphysis and the 3rd cervical vertebrae was considered into the relation by Bibby and Preston ${ }^{[7]}$. These slight variations hence did not cause a large variation in the samples. But in my relation the use of mobile structures will always cause a variation in the reading and hence the ideal head rest position and the use of non mobile skeletal tissue is a good factor to compare with. Eg. naso-maxiallry process.

The lower hyoid position in Class III malocclusion in relation to the anterior cranial base (SN plane) and the Frankfort plane (FH plane) could justify that the hyoid bone did not follow the mandibular movements completely. Thus it appears that, as the mandible is moved posteriorly in relation to the other cranofacial structures, the tongue and the hyoid bone do not follow this movement in a similar manner. Otherwise it would encroach upon the vital oropharyngeal and laryngeal spaces. As a functional compensation, the hyoid bone and related structures are guided to an inferior position to avoid compromising the airway space. This suggests the stability and potency of the pharyngeal airway are primary factors in the hyoid bone position. This is consistent with the results of Tourne ${ }^{[20]}$ and Battagel et al ${ }^{[31]}$.

Large distance between the hyoid bone and the cervical vertebrae( C3) in Class III subjects were similar to the study conducted by Michael and Donald ${ }^{[32]}$ and also Alhaija and Al Khateeb ${ }^{[33]}$ that showed that the hyoid bone moves more posteriorly with the increase in ANB angle. The explanation of this phenomenon lies with the genioglossus muscle that protrudes the tongue and generates upper airway dilating forces to maintain the patency and as the hyoid bone moved forward would pull the tongue anteriorly en mass, leading to increase in tongue pressure and maintaining the pharyngeal spaces at the level of the base of the tongue. Hence the hyoid bone is represented as the postural behaviour of the tongue. Thou the relation in the vertical plane showed no significance of the mandible with the hyoid bone (MPH).

The present study revealed that the relationship among the ANB angle and the hyoid bone position was reversely correlated in healthy patients which was a disagreement with different studies like Abu Alhaija et al ${ }^{[33]}$ and Arslan et al ${ }^{[12]}$. It also showed no significant statistical difference between different facial morphologies or growth patterns and the position of the hyoid bone and hence proving wrong in the basis of Jarabak's ratio which is one of the oldest and commonest used ratios for growth patterns and facial morphologies. The position of the Hyoid bone in class III patients is more anteriorly and inferiorly placed due to the prognathic mandible. According to the functional matrix theory the supra hyoid muscles that attach to the mandible and the tongue causes the hyoid bone to be more anteriorly placed and hence changes the position of the bone in relation to Class I patients. While in Class II the contracture of the supra hyoid muscles is lesser and the hence the hyoid is more posteriorly and superiorly placed. The role of the functional matrix theory can hence be described well with the correlation of the hyoid bone with the different skeletal malocclusion.

On the contrary due to the negative results of the position and orientation of the hyoid bone in various growth patterns the functional matrix theory can be contradicted on the same basis and stating that due to the rotation of the mandible the position of the hyoid bone and orientation to the mandible should change but this isn't so and hence gives a statistically non significant data and hence contradicts the theory otherwise.

If the hyoid bone is in the same position before and after orthodontic treatment, the soft tissue must still be in the same balance, thus possibly reducing the chance of relapse from the soft tissue forces. If the hyoid position is altered, a longer retention period than normal may be indicated. Any alteration in the hyoid position following mandibular surgery may be indicated for the balancing of the muscles forces to be made more favourable by myectomy or myotomy to reduce surgical relapse.

\section{Conclusion:-}

1. The hyoid bone position and orientation is different according to different skeletal malocclusions.

2. In class III malocclusion, the hyoid bone is more anteriorly and inferiorly placed.

3. In class II malocclusion, the hyoid bone position is more posterior and more superior.

4. The anteroposterior dimensions in different class malocclusions is constant

5. No relationship could be found between different facial morphologies and hyoid bone position and orientation. 


\section{Acknowledgements:-}

Authors would like to acknowledge the full staff of the Orthodontic department of Bharati Vidhyapeeth Dental college and hospital, Pune for providing the material required for the scientific research. We would like to thank Mrs. Aruna Deshpande in her guidance for the statistical tests.

\section{References:-}

1. Efendiyeva R(2014). Pharyngeal airway space, hyoid bone position, and head posture after bimaxillary orthognathic surgery in Class III patients: long-term evaluation. Angle Orthod. 2014 Sep;84(5):773-81.

2. Eggensperger N, Smolka W, Iizuka T. Long-term changes of hyoid bone position and pharyngeal airway size following mandibular setback by sagittal split ramus osteotomy. Journal of Cranio-Maxillofacial Surgery. 2005;33(2):111-117.

3. Romanes GJ. Cunningham's Manual of Practical Anatomy. 14th edition. Vol. 3. New York, NY, USA: Oxford University Press; 1983

4. Gray, H. (1954): Anatomy of the Human Body, Philadelphia, Lea \& Febiger, pp. 194-195.

5. Yamaoka M, Furusawa K, Uematsu T, Okafuji N, Kayamoto D, Kurihara S. (2003) Relationship of the hyoid bone and posterior surface of the tongue in prognathism and micrognathia. J Oral Rehabil.30(9):914-20. doi: 10.1046/j.1365-2842.2003.01069.x.

6. Brodie AG(1950): Anatomy and physiology of head and neck musculature. Am J Orthod. 36: 831-44.

7. Bibby RE, Preston CB. (1981) The Hyoid triangle. Am J Orthod. 80: 92-7.

8. Porntip PS, Jarabak JR (1985): Malocclusion and Facial Morphology Is there a relationship?- An Epidemiological study. Angles Orthodontics April

9. Schwarz AM (1960) Roentgenostatics New York: Leo L. Bruder

10. Schudy $\mathrm{FF}(1965)$ : The rotation of the mandible resulting from growth: its implications in orthodontic treatment. Angle Orthod. Jan;35:36-50.

11. Broadbent, Sr., B.H.; Broadbent, Jr., B.H., and Golden, W. (1975): Bolton standards of dentofacial developmental growth. The C.V. Mosby Company, Saint Louis USA.

12. Arslan SG (2014): Cephalometric Investigation of First Cervical Vertebrae Morphology and Hyoid Position in Young Adults with Different Sagittal Skeletal Patterns. doi: 10.1155/2014/159784.

13. Amayeri M (2014): The Position of Hyoid Bone in different Facial Patterns: A lateral cephalometric study. European Scientific Journal May vol.10, No.15 ISSN: 1857 - 7881 (Print) e - ISSN 1857- 7431.

14. Galvão CA(1983): Hyoid Bone's cephalometric positional study in normal occlusion and in malocclusion patients. Rev.Odont. UNESP . São Paulo 12(1/2):143-152

15. King, E. W. (1952): A roentgenographic study of pharyngeal growth, Angle Orthod. 22: 23

16. Bench, R. W. (1963): Growth of the cervical vertebrae as related to tongue, face, and denture behavior, AM. J. ORTHOD.49: 183

17. Bibby, R. E.(1979): The position of the hyoid bone in orthodontic patients, Master's thesis, University of the Witwatersrand.

18. Grant, L. E.(1959): A radiographic study of hyoid bone position in Angle's Class I, II, and Ill malocclusions, Master's thesis, University of Kansas City.

19. Smith JL (1965) - A cephalometric radiographic study of the position of the hyoid bone in rela- tion to the mandib/e in certain functional position. Evanston, Northwestern University, 1956. (Master's Thesis). Apud STEPOVICH, M.L.

20. Stepovich, M. L.(1965): A cephalometric positional study of the hyoid bone, AM. J. ORTHOD.51: 882.

21. Ingervall, B., Carlsson, G. E., and Helkimo, M.(1970): Changes in location of the hyoid bone with mandibular positions, Acta Odontol. \&and. 28: 337.

22. Adamidis IP, Spyropoulos MN. (1992) Hyoid bone position and orientation in Class I and Class III malocclusions. Am J Orhdod Dentofacial Orthop. 1992; 101: 308-12.

23. Opdebeeck H, Bell WH, Eisenfeld J, Michelevich D. (1978) Comparative study between the SFS and LFS rotation as a possible morphogenic mechanism. Am J Orthod. 74:509-521

24. Profit WR- Equilibrium Theory Revisited: Factors Incfluencing Position of the Teeth. 1977 biennial meeting of the Angle Society, Department of Orthodontics, Univ. of North Carolina.

25. Fromm B, Lundberg M. (1970) Postural behaviour of the hyoid bone in normal occlusion and before and after surgical correction of mandibular protrusion. Swedish Dental Journal.63(6):425-433.

26. Haralabakis NB, Toutountzakis NM, Yiagtzis SC.(1993) The Hyoid bone position in adult individuals with open bite and normal occlusion. Eur J Orthod. 15: 265-71. 
27. Subtelny JD, Sakuda M. (1964) Open-bite: Diagnosis and treatment. Am J Orthod 50:337-358

28. Thompson, I. R.(1941): A cephalometric study of the movements of the mandible, J. Am. Dent. Assoc. 28: 750.

29. Graber, L.(1978): Hyoid changes following orthopedic treatment of mandibular prognatbism, Angle Orthod. 48:33.

30. Tourné LPM. (1991): Growth of the pharynx and its physiologic implications. Am. J. Orthod. . 99:129-139.

31. Battagel JM, Johal A, L'Estrange PR, Croft CB and Kotecha B. (1999): Changes in airway and hyoid position in response to mandibular protrusion in subjects with obstructive sleep apnoea (OSA). Eur J Orthod. Aug; 21(4):363-76.

32. Michael J. Trenouth and Donald J. Timms. (1999): Relationship of the functional oropharynx to craniofacial morphology. The Angle Orthodontist: Vol. 69, No. 5, pp. 419-423.

33. Abu Alhaija Elham S. J., Al Wahadni Ahed M. S. and Al Omari Mohammad A. O. (2002): Uvulo-glossopharyngeal dimensions in subjects with $\beta$ - thalassaemia major. European Journal of Orthodontics. 24.699-703.

34. Abu Alhaija Elham Saleh and Al-Khateeb Susan Nadeem. (2005): Uvulo- glosso-pharyngeal dimensions in different anteroposterior skeletal patterns. The Angle Orthodontist: Vol. 75, No. 6, pp. 1012-1018. 
Table 3:- Hyoid data - mean \& standard deviation.

\begin{tabular}{|c|c|c|c|c|}
\hline & & $\mathrm{N}$ & Mean & Std. Deviation \\
\hline \multirow[t]{4}{*}{$\mathrm{H}-\mathrm{SN}$} & Class I & 20 & 89.40 & \pm 7.694 \\
\hline & Class II & 20 & 84.85 & \pm 7.755 \\
\hline & Class III & 20 & 90.20 & \pm 7.150 \\
\hline & Total & 60 & 88.15 & \pm 7.781 \\
\hline \multirow[t]{4}{*}{ H-FH } & Class I & 20 & 74.75 & \pm 7.587 \\
\hline & Class II & 20 & 68.00 & \pm 7.553 \\
\hline & Class III & 20 & 71.80 & \pm 8.618 \\
\hline & Total & 60 & 71.52 & \pm 8.282 \\
\hline \multirow[t]{4}{*}{$\mathrm{H}-\mathrm{NL}$} & Class I & 20 & 54.75 & \pm 8.873 \\
\hline & Class II & 20 & 46.50 & \pm 5.624 \\
\hline & Class III & 20 & 51.60 & \pm 4.235 \\
\hline & Total & 60 & 50.95 & \pm 7.285 \\
\hline \multirow[t]{4}{*}{ H-Pog } & Class I & 20 & 51.25 & \pm 7.840 \\
\hline & Class II & 20 & 43.40 & \pm 5.315 \\
\hline & Class III & 20 & 40.50 & \pm 4.007 \\
\hline & Total & 60 & 45.05 & \pm 7.418 \\
\hline \multirow[t]{4}{*}{$\mathrm{H}-\mathrm{Me}$} & Class I & 20 & 47.65 & \pm 7.982 \\
\hline & Class II & 20 & 39.35 & \pm 4.859 \\
\hline & Class III & 20 & 37.80 & \pm 4.047 \\
\hline & Total & 60 & 41.60 & \pm 7.240 \\
\hline \multirow[t]{4}{*}{ H-ML } & Class I & 20 & 11.40 & \pm 3.803 \\
\hline & Class II & 20 & 9.80 & \pm 2.821 \\
\hline & Class III & 20 & 10.90 & \pm 1.334 \\
\hline & Total & 60 & 10.70 & \pm 2.872 \\
\hline \multirow[t]{4}{*}{$\mathrm{H}-\mathrm{C} 3$} & Class I & 20 & 31.60 & \pm 3.378 \\
\hline & Class II & 20 & 29.35 & \pm 2.498 \\
\hline & Class III & 20 & 32.00 & \pm 2.471 \\
\hline & Total & 60 & 30.98 & \pm 3.006 \\
\hline \multirow[t]{4}{*}{ ANB } & Class I & 20 & 2.70 & \pm 1.865 \\
\hline & Class II & 20 & 6.10 & \pm 1.334 \\
\hline & Class III & 20 & -4.25 & \pm 2.863 \\
\hline & Total & 60 & 1.52 & \pm 4.725 \\
\hline \multirow[t]{4}{*}{ SNA } & Class I & 20 & 79.60 & \pm 3.440 \\
\hline & Class II & 20 & 83.75 & \pm 4.767 \\
\hline & Class III & 20 & 80.50 & \pm 3.954 \\
\hline & Total & 60 & 81.28 & \pm 4.404 \\
\hline \multirow[t]{4}{*}{ SNB } & Class I & 20 & 76.90 & \pm 3.493 \\
\hline & Class II & 20 & 77.85 & \pm 4.727 \\
\hline & Class III & 20 & 84.80 & \pm 4.851 \\
\hline & Total & 60 & 79.85 & \pm 5.596 \\
\hline \multirow[t]{4}{*}{$\mathrm{SNH}$} & Class I & 20 & 50.50 & \pm 3.692 \\
\hline & Class II & 20 & 53.90 & \pm 4.266 \\
\hline & Class III & 20 & 60.10 & \pm 4.436 \\
\hline & Total & 60 & 54.83 & \pm 5.714 \\
\hline \multirow[t]{4}{*}{$\mathrm{MPH}$} & Class I & 20 & 15.25 & \pm 5.250 \\
\hline & Class II & 20 & 13.05 & \pm 4.032 \\
\hline & Class III & 20 & 14.60 & \pm 3.050 \\
\hline & Total & 60 & 14.30 & \pm 4.240 \\
\hline
\end{tabular}


Table 3(i):- p-values.

\begin{tabular}{|c|c|c|c|}
\hline Dependent Variable & Pairs & p-value & Significance \\
\hline \multirow{3}{*}{$\begin{array}{l}\text { H-NSL } \\
0.061\end{array}$} & Class I \& II & 0.145 & NS \\
\hline & Class I \& III & 0.940 & NS \\
\hline & Class II \& III & 0.072 & NS \\
\hline \multirow{3}{*}{$\begin{array}{l}\text { H-FH } \\
\mathbf{0 . 0 3 3} *\end{array}$} & Class I \& II & 0.025 & Significant \\
\hline & Class I \& III & 0.472 & NS \\
\hline & Class II \& III & 0.292 & NS \\
\hline \multirow{3}{*}{$\begin{array}{l}\text { H-NL } \\
\text { 0.001* }\end{array}$} & Class I \& II & 0.001 & Significant \\
\hline & Class I \& III & 0.288 & $\mathrm{NS}$ \\
\hline & Class II \& III & 0.043 & Significant \\
\hline \multirow{3}{*}{$\begin{array}{l}\text { H-POG } \\
\text { 0.000* }\end{array}$} & Class I \& II & 0.000 & Significant \\
\hline & Class I \& III & 0.000 & Significant \\
\hline & Class II \& III & 0.278 & NS \\
\hline \multirow{3}{*}{$\begin{array}{l}\mathrm{H}-\mathrm{ME} \\
\text { 0.000* }\end{array}$} & Class I \& II & 0.000 & Significant \\
\hline & Class I \& III & 0.000 & Significant \\
\hline & Class II \& III & 0.684 & NS \\
\hline \multirow{3}{*}{$\begin{array}{l}\text { H-ML } \\
0.199\end{array}$} & Class I \& II & 0.185 & NS \\
\hline & Class I \& III & 0.843 & NS \\
\hline & Class II \& III & 0.444 & NS \\
\hline \multirow{3}{*}{$\begin{array}{l}\mathrm{H}-\mathrm{C} 3 \\
\text { 0.009* }\end{array}$} & Class I \& II & 0.037 & Significant \\
\hline & Class I \& III & 0.895 & NS \\
\hline & Class II \& III & 0.012 & Significant \\
\hline \multirow{3}{*}{$\begin{array}{l}\text { ANB } \\
\text { 0.000* }\end{array}$} & Class I \& II & 0.000 & Significant \\
\hline & Class I \& III & 0.000 & Significant \\
\hline & Class II \& III & 0.000 & Significant \\
\hline \multirow{3}{*}{$\begin{array}{l}\text { SNA } \\
\text { 0.006* }\end{array}$} & Class I \& II & 0.006 & Significant \\
\hline & Class I \& III & 0.767 & NS \\
\hline & Class II \& III & 0.039 & Significant \\
\hline \multirow{3}{*}{$\begin{array}{l}\text { SNB } \\
0.000 *\end{array}$} & Class I \& II & 0.774 & $\mathrm{NS}$ \\
\hline & Class I \& III & 0.000 & Significant \\
\hline & Class II \& III & 0.000 & Significant \\
\hline \multirow{3}{*}{$\begin{array}{l}\text { SNH } \\
\text { 0.000* }\end{array}$} & Class I \& II & 0.032 & Significant \\
\hline & Class I \& III & 0.000 & Significant \\
\hline & Class II \& III & 0.000 & Significant \\
\hline \multirow{3}{*}{$\begin{array}{l}\text { MPH } \\
0.245\end{array}$} & Class I \& II & 0.232 & NS \\
\hline & Class I \& III & 0.877 & NS \\
\hline & Class II \& III & 0.479 & NS \\
\hline
\end{tabular}




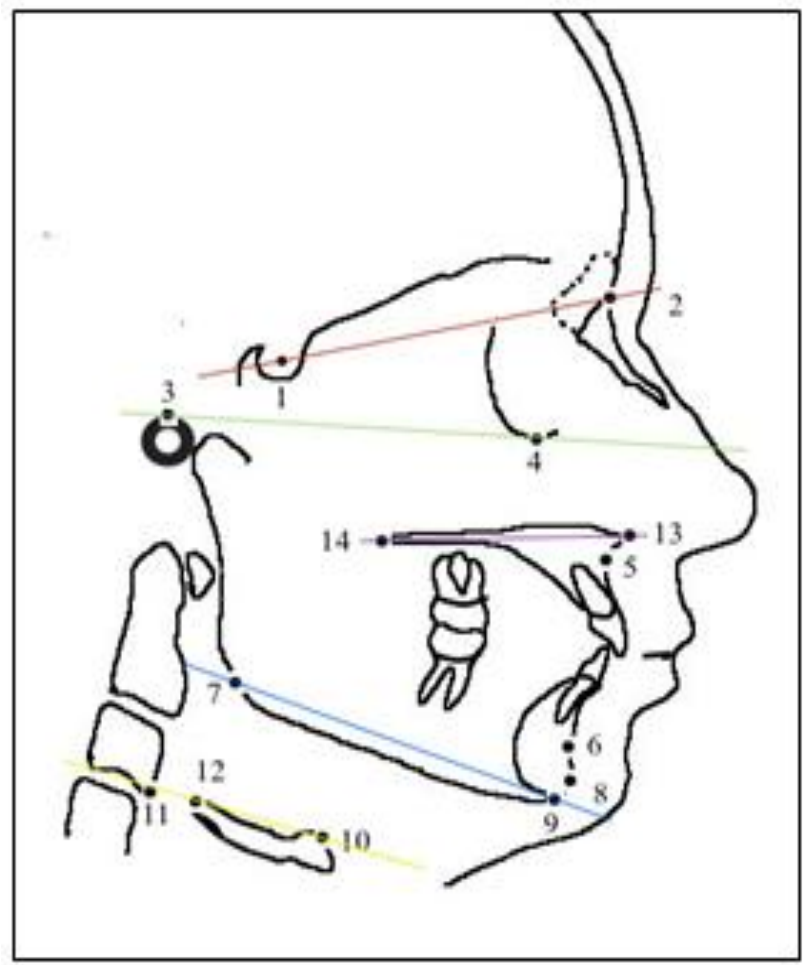

Fig 1:-Various cephalometric landmarks and planes thats are required for tracing of the cephalograms. 1: Sella Turcica (S), 2: Nasion (N), 3: Porion (P), 4: Orbitale (O), 5: Subspinale (point A), 6: Supramentale (point B), 7: Gonion (Go), 8: Gnathion (Gn), 9: Menton (Me), 10: Hyoidale (H), 11: C3, 12: Hy'(Hy'point), 13: Anterior Nasal Spine (ANS), 14: Posterior Nasal Spine (PNS).Red line: SN plane, Green line: FH plane, Purple line: Nasal Line, Blue line: Mandibular plane, Yellow Line: Hyoid Axis.

Graph 1: Mean Hyoid Parameters by Angle's malocclusion

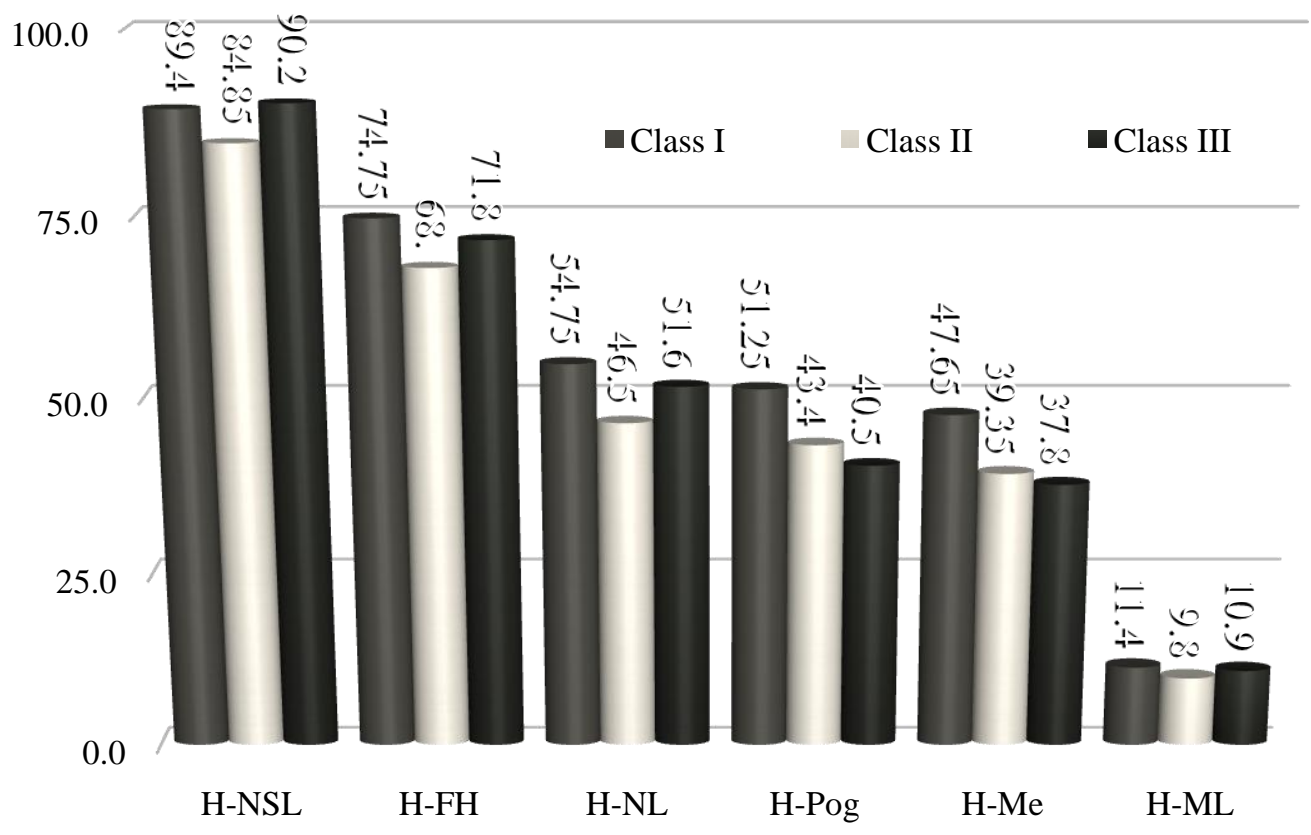


Table 4:- Growth Patterns - mean \& standard deviation.

\begin{tabular}{|c|c|c|c|c|}
\hline & & $\mathrm{N}$ & Mean & Std. Deviation \\
\hline \multirow[t]{4}{*}{ H-NSL } & Hypodivergent(Ho) & 24 & 87.63 & 8.968 \\
\hline & Hyperdivergent(Hp) & 16 & 92.56 & 5.876 \\
\hline & Neutral (Nt) & 17 & 87.53 & 7.169 \\
\hline & Total & 57 & 88.98 & 7.877 \\
\hline \multirow[t]{4}{*}{ H-FH } & Hypodivergent(Ho) & 24 & 71.38 & 8.096 \\
\hline & Hyperdivergent $(\mathrm{Hp})$ & 16 & 73.75 & 7.878 \\
\hline & Neutral (Nt) & 17 & 70.76 & 8.920 \\
\hline & Total & 57 & 71.86 & 8.232 \\
\hline \multirow[t]{4}{*}{$\mathrm{H}-\mathrm{NL}$} & Hypodivergent(Ho) & 24 & 50.79 & 8.209 \\
\hline & Hyperdivergent(Hp) & 16 & 52.75 & 6.777 \\
\hline & Neutral (Nt) & 17 & 50.65 & 6.451 \\
\hline & Total & 57 & 51.30 & 7.260 \\
\hline \multirow[t]{4}{*}{ H-Pog } & Hypodivergent(Ho) & 24 & 44.33 & 9.102 \\
\hline & Hyperdivergent(Hp) & 16 & 44.44 & 5.416 \\
\hline & Neutral (Nt) & 17 & 45.29 & 7.218 \\
\hline & Total & 57 & 44.65 & 7.546 \\
\hline \multirow[t]{4}{*}{ H-Me } & Hypodivergent(Ho) & 24 & 41.17 & 8.991 \\
\hline & Hyperdivergent(Hp) & 16 & 41.75 & 4.389 \\
\hline & Neutral (Nt) & 17 & 41.76 & 7.049 \\
\hline & Total & 57 & 41.51 & 7.256 \\
\hline \multirow[t]{4}{*}{ H-ML } & Hypodivergent(Ho) & 24 & 10.29 & 3.420 \\
\hline & Hyperdivergent $(\mathrm{Hp})$ & 16 & 11.38 & 1.857 \\
\hline & Neutral (Nt) & 17 & 10.59 & 2.526 \\
\hline & Total & 57 & 10.68 & 2.785 \\
\hline \multirow[t]{4}{*}{$\mathrm{H}-\mathrm{C} 3$} & Hypodivergent(Ho) & 24 & 31.04 & 3.884 \\
\hline & Hyperdivergent(Hp) & 16 & 30.25 & 1.342 \\
\hline & Neutral (Nt) & 17 & 30.71 & 1.160 \\
\hline & Total & 57 & 30.72 & 2.678 \\
\hline \multirow[t]{4}{*}{$\mathrm{SNH}$} & Hypodivergent(Ho) & 24 & 55.83 & 5.088 \\
\hline & Hyperdivergent $(\mathrm{Hp})$ & 16 & 55.19 & 6.002 \\
\hline & Neutral (Nt) & 17 & 54.82 & 6.167 \\
\hline & Total & 57 & 55.35 & 5.598 \\
\hline \multirow[t]{4}{*}{$\mathrm{MPH}$} & Hypodivergent(Ho) & 24 & 13.88 & 3.768 \\
\hline & Hyperdivergent(Hp) & 16 & 14.81 & 2.689 \\
\hline & Neutral (Nt) & 17 & 14.88 & 5.743 \\
\hline & Total & 57 & 14.44 & 4.175 \\
\hline
\end{tabular}


Graph 2: Mean Hyoid Parameters by Facial morphologies

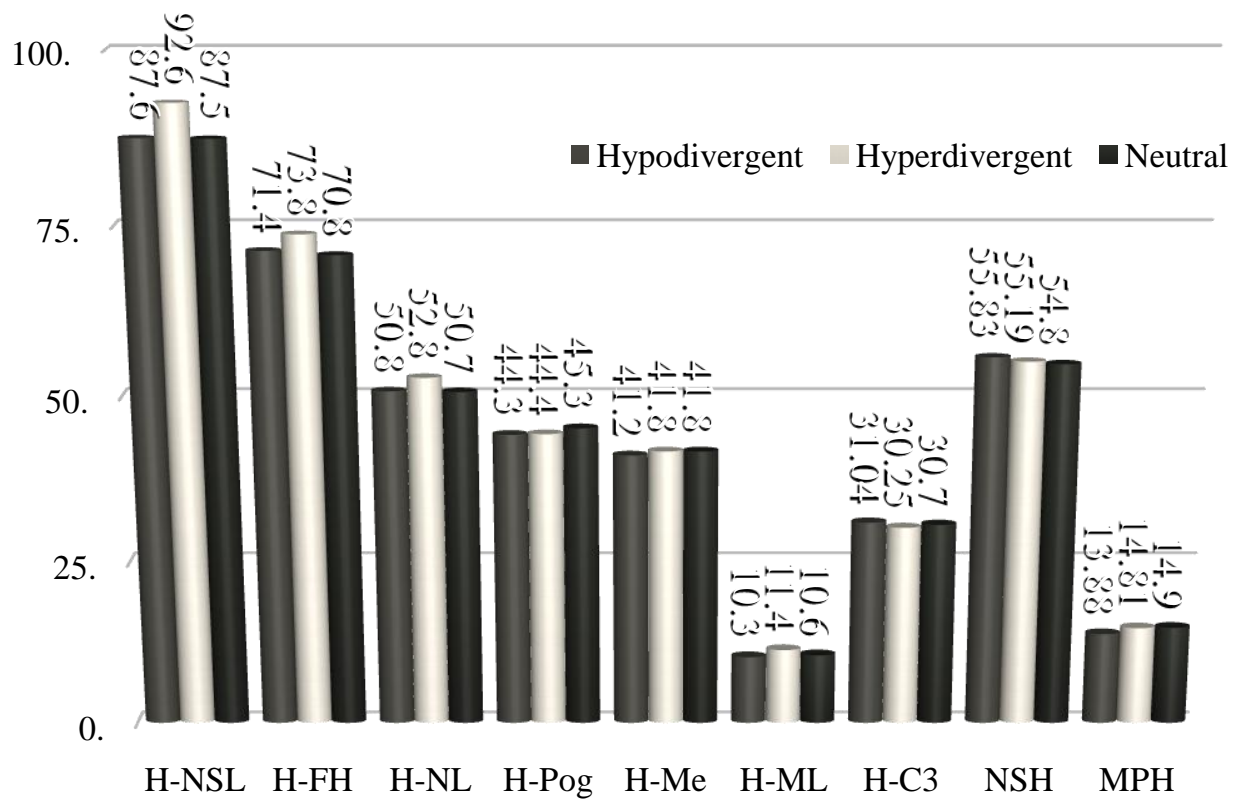

Table 4 (i):- p-values.

\begin{tabular}{|c|c|c|c|}
\hline Dependent Variable & Pairs & $\mathrm{p}$-value & Significance \\
\hline \multirow{3}{*}{$\begin{array}{l}\text { H-NSL } \\
0.099\end{array}$} & Ho \& Hp & 0.124 & NS \\
\hline & Ho \& Nt & 0.999 & NS \\
\hline & $\mathrm{Hp} \& \mathrm{Nt}$ & 0.154 & NS \\
\hline \multirow{3}{*}{$\begin{array}{l}\text { H-FH } \\
0.550\end{array}$} & Ho \& Hp & 0.650 & NS \\
\hline & Ho \& Nt & 0.971 & NS \\
\hline & $\mathrm{Hp} \& \mathrm{Nt}$ & 0.559 & NS \\
\hline \multirow{3}{*}{$\begin{array}{l}\text { H-NL } \\
0.648\end{array}$} & Ho \& Hp & 0.688 & NS \\
\hline & Ho \& Nt & 0.998 & NS \\
\hline & $\mathrm{Hp} \& \mathrm{Nt}$ & 0.690 & NS \\
\hline \multirow{3}{*}{$\begin{array}{l}\text { H-POG } \\
0.917\end{array}$} & Ho \& Hp & 0.999 & NS \\
\hline & Ho \& Nt & 0.918 & NS \\
\hline & $\mathrm{Hp} \& \mathrm{Nt}$ & 0.945 & NS \\
\hline \multirow{3}{*}{$\begin{array}{l}\mathrm{H}-\mathrm{Me} \\
0.956\end{array}$} & Ho \& Hp & 0.968 & NS \\
\hline & Ho \& Nt & 0.965 & NS \\
\hline & $\mathrm{Hp} \& \mathrm{Nt}$ & 1.000 & NS \\
\hline \multirow{3}{*}{$\begin{array}{l}\text { H-ML } \\
0.485\end{array}$} & Ho \& Hp & 0.459 & NS \\
\hline & Ho \& Nt & 0.940 & NS \\
\hline & $\mathrm{Hp} \& \mathrm{Nt}$ & 0.700 & NS \\
\hline \multirow{3}{*}{$\begin{array}{l}\mathrm{H}-\mathrm{C} 3 \\
0.665\end{array}$} & Ho \& Hp & 0.639 & NS \\
\hline & Ho \& Nt & 0.919 & NS \\
\hline & $\mathrm{Hp} \& \mathrm{Nt}$ & 0.879 & NS \\
\hline \multirow{3}{*}{$\begin{array}{l}\text { SNH } \\
0.847\end{array}$} & Ho \& Hp & 0.934 & NS \\
\hline & Ho \& Nt & 0.842 & NS \\
\hline & $\mathrm{Hp} \& \mathrm{Nt}$ & 0.982 & NS \\
\hline \multirow{3}{*}{$\begin{array}{l}\text { MPH } \\
0.692\end{array}$} & Ho \& Hp & 0.772 & NS \\
\hline & Ho \& Nt & 0.733 & NS \\
\hline & $\mathrm{Hp} \& \mathrm{Nt}$ & 0.999 & NS \\
\hline
\end{tabular}

